\title{
Large Core Three Branch Polymer Power Splitters
}

\author{
Vaclav PRAJZLER ${ }^{1}$, Radek MASTERA ${ }^{1}$, Jarmila SPIRKOVA ${ }^{2}$ \\ ${ }^{1}$ Dept. of Microelectronics, Czech Technical University, Technická 2, 16827 Prague, Czech Republic \\ ${ }^{2}$ Institute of Chemical Technology, Technická 5, 16627 Prague, Czech Republic \\ xprajzlv@feld.cvut.cz
}

\begin{abstract}
We report about three branch large core polymer power splitters optimized for connecting standard plastic optical fibers. A new point of the design is insertion of a rectangle-shaped spacing between the input and the central part of the splitter, which will ensure more even distribution of the output optical power. The splitters were designed by beam propagation method using BeamPROP software. Acrylic-based polymers were used as optical waveguides being poured into the Y-grooves realized by computer numerical controlled engraving on poly(methylmethacrylate) substrate. Measurement of the optical insertion losses proved that the insertion optical loss could be lowered to $2.1 \mathrm{~dB}$ at $650 \mathrm{~nm}$ and optical power coupling ratio could reach $31.8 \%: 37.3 \%: 30.9 \%$.
\end{abstract}

\section{Keywords}

Optical planar waveguides, multimode waveguides, optical splitter, beam propagation method, polymer

\section{Introduction}

Optical power branching splitters are key passive components used for distribution and processing of optical signals. The simplest optical branching splitter is Y-junction with one input and two output ports [1], [2]. The conventional symmetrical $\mathrm{Y}$-junctions have even number of output waveguides. As realizations of similar devices are usually done by linking two-branch waveguides the number of the output ports increases the dimensions of such splitters. Branching splitters with non-symmetrical output distribution of optical power [1] and those with odd number of output waveguides with symmetrical optical power distribution [1] have been described as well. In a conventional three-branch splitter with a uniform index distribution most of the power is concentrated in central branch. Up to now only few papers dealing with realization of three-branch planar splitters with symmetrical power distribution have been presented [1]. Principle of one of them [3] is based on a conventional structure with a central branch as a triangularly shaped spacing area. This area has lower refractive index than that of the waveguides and its function is to reduce the transmission coefficient between the main waveguide and the central branch (see Fig. 1a).
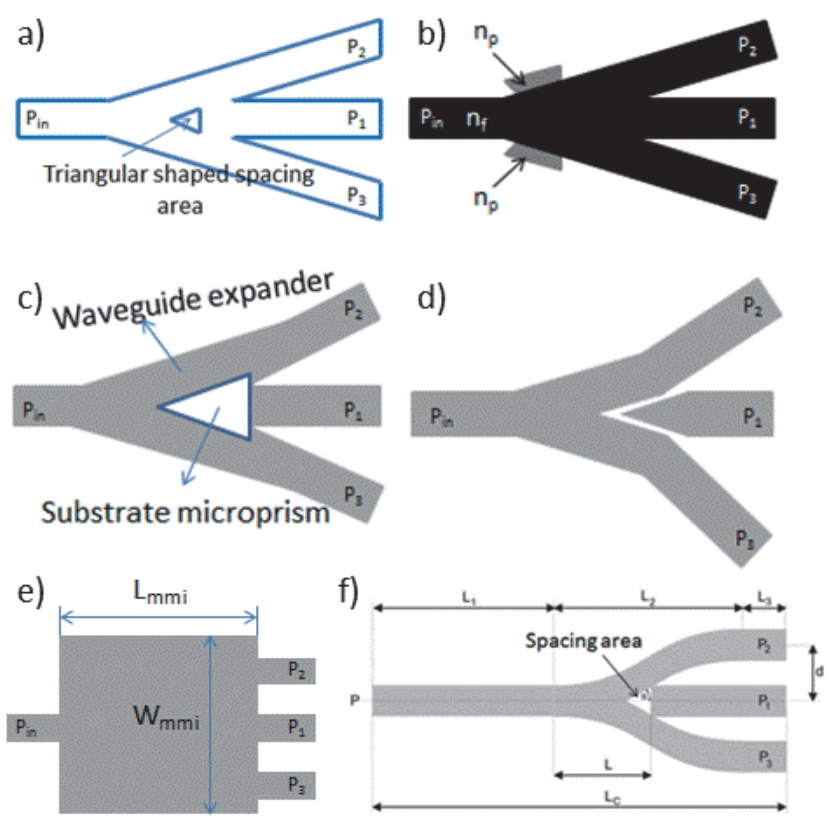

Fig. 1. Schematic view of the published 1x3 splitters:
a) splitter with a triangular shaped spacing area [3],
b) splitter with a microprism [4],
c) splitter using substrate microprisms and waveguide expanders [5],
d) fork-type splitter [6],
e) splitter using multimode interference [7], [8],
f) the proposed $1 \times 3 \mathrm{Y}$ splitters with triangular shaped spacing [19].

Another possibility to achieve symmetrical dividing is using of microprisms that are applied to modify the wave front of incoming waves more efficiently to facilitate wave branching at large angles [4]. This structure differs from the conventional structure in that that pair of microprisms is provided at the junction of the input and output waveguides (see Fig. 1b). Also a wide-angle 1x3Y optical power splitter with variable power splitting using substrate microprisms and two waveguide expanders made by nickel diffusion into $\mathrm{LiNbO}_{3}$ single-crystalline substrate (see Fig. 1c) has been demonstrated in [5]. Fork-type threebranch optical power splitters consisting of only two different dielectric materials reported in [6] consisted of a symmetric Y-branch waveguide with a phase front retarder and a center branch located a coupling gap apart (see Fig. 1d). Simulations showed that such a waveguide with a larger index difference had lower radiation losses for a wider branching angle. Another possibility for optical 
signal distribution between the channels is using of multimode interference (MMI) splitters [7], [8]. Compared with concatenations of junction splitters, the MMI splitters are attractive alternatives because of their low excess loss and ultra-compact dimension, but the disadvantage of such structure is a small bandwidth. Schematic view of the $1 \times 3$ MMI wavelength power splitter is shown in Fig. 1e.

Various materials have been used in realizing the optical splitters, mainly optical glass, crystals, silica, silicon and semiconductors [9-11]. These types of the splitters have suitable properties but the deposition technologies needed for their fabrications are complicated, expensive and environment unfriendly. In the last few years new polymer materials have become to be used for novel photonics structures in a wide range of applications. It is because polymers offer many advantages over traditional materials mainly high optical clarity, low attenuation, suitable refractive index, easy fabrication process and low cost [12-18].

While the structures showed in Fig. 1e have been already realized in the polymer-based materials, the splitter shown in Fig. 1a-d has not been yet presented in any polymer materials. All of the above mentioned splitters with three output waveguides have been proposed for single mode waveguides and no multi-mode based structures have been yet presented.

We have already reported about the design of a single mode polymer $1 \times 3 \mathrm{Y}$ splitter [19] with triangular shaped spacing inserted between the input and the central output branches (see Fig. 1f), which was to provide a symmetrical distribution of the optical power between the output branches. Also we reported on the design, fabrication and properties of multimode polymer $1 \mathrm{x} 2 \mathrm{Y}$ and $1 \mathrm{x} 4 \mathrm{Y}$ splitters designed by ray tracing [20] and beam propagation method (BPM) [21], [22].

In this paper we are going to present our new approach to construct polymer large core power splitters with one input and three outputs plastic optical fiber (POF). The novelty of our approach is in inserting of a rectangle between the input and the central part of the splitter, which is to ensure more proportional distribution of the outgoing optical power. The design was done by BPM method with help of BeamPROP program in the frame of the specialized simulation package MOST, (RSoft's, Multi-Variable Optimization and Scanning Tool) for acrylic-based polymer used as a waveguide core material and poly(methyl methacrylate) (PMMA) as a substrate and cover layer.

\section{Modeling of the Large Core 1x3Y Power Splitters}

Optical waveguide structure used for designing the optical splitter is the step-index rectangular waveguide consisting of a waveguide core layer of refractive index $n_{\mathrm{f}}$, surrounded in all sides by materials having refractive index $n_{\mathrm{c}}$ lower than that of the core waveguide (see Fig. 2).

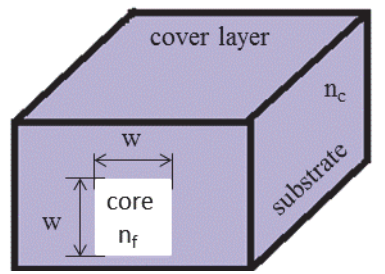

Fig. 2. Cross-sectional view of the proposed large core optical rectangular waveguide.

Prior the modeling we measured refractive indices of the applied materials by Metricon 2010 prism-coupler system, which measures at five wavelengths (see Tab. 1). As the measurement at $650 \mathrm{~nm}$ was not available by the apparatus, the needed data for $650 \mathrm{~nm}$ were extrapolated from the obtained data (see Tab. 1).

\begin{tabular}{|c|c|c|c|c|}
\hline \multirow{2}{*}{$\begin{array}{c}\text { Wavelength } \\
\text { (nm) }\end{array}$} & \multicolumn{4}{|c|}{ Refractive index (-) } \\
\cline { 2 - 5 } & PMMA & NOA88 & NOA73 & NOA1625 \\
\hline 473 & 1.4987 & 1.5710 & 1.5721 & 1.6427 \\
\hline 632.8 & 1.4897 & 1.5574 & 1.5586 & 1.6262 \\
\hline 964 & 1.4835 & 1.5501 & 1.5482 & 1.6135 \\
\hline 1311 & 1.481 & 1.5478 & 1.5431 & 1.6079 \\
\hline 1552 & 1.4799 & 1.5461 & 1.5412 & 1.6064 \\
\hline
\end{tabular}

Tab. 1. The values of the refractive indices of the applied materials measured by optical prism-coupler system Metricon 2010.

Suitability of the polymer materials proposed for the cores of the planar waveguides was checked by measuring of their transmission spectra by UV-VIS-NIR Spectrometer Shimadzu. This measurement showed that NOA materials were transparent within the range from $400 \mathrm{~nm}$ to $1600 \mathrm{~nm}$.

Dimensions of the rectangular waveguide were set so that it could be connected to a standard plastic optical fiber (POF) with core diameter $980 \mu \mathrm{m}$ and $20 \mu \mathrm{m}$ thick cladding layer.

We started with designing of optical splitters with two output waveguides and prosecuted to three output splitters. Geometrical dimensions of the two-output splitters were calculated by analysis for a lossless Y-junction published by Beltrami [23] (this design we published in [20-22]) and then we intended to extend the design to a three-output variety. To achieve it we had to widen the distance (gap) between the two original output waveguides to insert the third central waveguide, as connecting three large core output fiber waveguides needs its space. For all our designed structures we used PMMA substrates and three different core-waveguide layers (NOA - Norland Optical Adhesives).

Basic configuration of the proposed multimode threebranch optical splitter is shown in Fig. 3a while Fig. 3b shows our proposed splitter where the rectangle shaped spacing is inserted between the input and the central output branches. The rectangle is made of the same material as the substrate (PMMA) and allows for providing more proportional distribution of the outgoing optical power.

Results of the simulations of the basic multimode three-branch optical splitter for NOA73 core waveguide 
layer are shown in Fig. $4 \mathrm{a}$ and that for NOA1625 are shown in Fig. 4b.

The simulations were done by BPM using BeamPROP software. We applied 2D dimensional channel with multimode source operating at $650 \mathrm{~nm}$. The modeling was done for refractive indices of 1.558 (waveguide NOA73 layer), 1.625 (waveguide NOA1625 layer) and 1.489 (PMMA substrate), respectively. Both simulations show that the power division is non-symmetrical. As could be expected the central waveguide branch of the NOA73 transmits more optical power $P_{2}$ than the left $P_{1}$ and right $P_{3}$ output waveguides, which corresponds to their splitting ratio: central branch $35.4 \%\left(P_{2}\right)$ : left branch $31.6 \%\left(P_{1}\right)$ : right branch $33.0 \%\left(P_{3}\right)$ (see Fig. $4 \mathrm{a}$ ). Figure $4 \mathrm{~b}$ shows the splitting ratio of NOA1625 is $31.2 \%: 35.2 \%: 33.5 \%\left(P_{1}\right.$ : $P_{2}: P_{3}$, resp.).

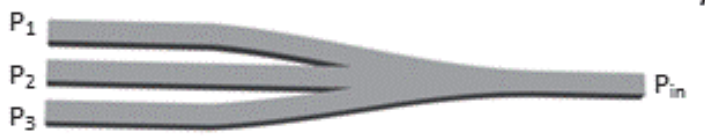

b)

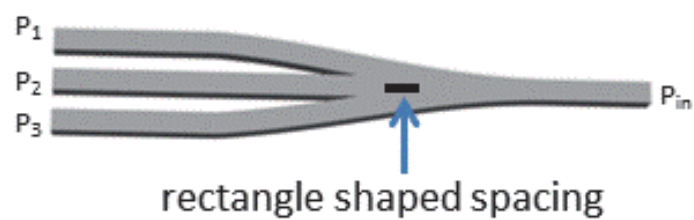

Fig. 3. a) Geometrical structure of the $1 \times 3 \mathrm{Y}$ optical power splitter, b) three-branch optical power splitter with rectangle shaped spacing.

a)

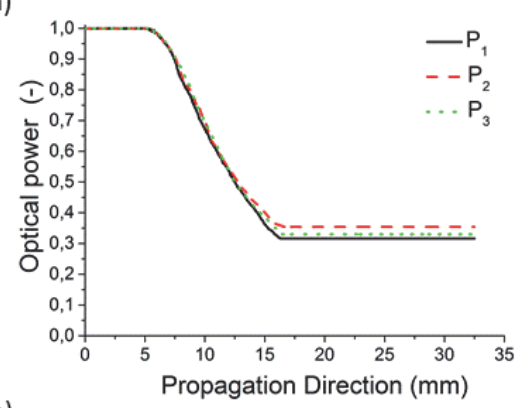

b)

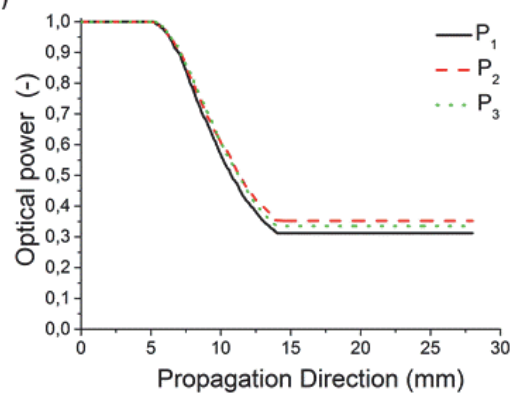

Fig. 4. Normalized optical signal propagation $(\lambda=650 \mathrm{~nm})$ for the $1 \times 3 Y$ splitter obtained by BPM simulation with photopolymer waveguide layer, a) NOA73, b) NOA1625.

\section{Design of the Three Branch Splitters with Rectangle Shaped Spacing}

As was shown in the previous sections normally in the three-branch optical splitter with a uniform refractive index distribution the most of the optical power will be predominantly driven via the central branch. To provide more proportional distribution of the power we proposed an optical splitter with an inserted rectangle shaped spacing area between the input and the central output branch. This rectangle is made from the same materials (PMMA) as the surrounding core materials. Our design also aimed to optimize the dimension of the rectangle shaped spacing and to find the optimal position for this to achieve proportional $1 \times 3 Y$ power splitting. For that optimization we again used BPM simulation for operating wavelength of $650 \mathrm{~nm}$ (using MOST).

In the reference structure without the inserted rectangle (see Fig. 3a) the output powers in the particular output waveguides differed at least in $5 \%$, which is quite far from being symmetrical.

The results of the simulations for the optimized structure for NOA73 waveguides with rectangle shaped spacing area are shown in Fig. 5. Figure 5a shows the computed refractive index profile of the optimized structure with the pertinent dimensions while the propagation of the signal is given in Fig. 5b. The modeling was done for the wavelength of $650 \mathrm{~nm}$ and for refractive indices of 1.558 (waveguide NOA73 layer) and 1.489 (PMMA substrate), respectively. From Fig. $5 \mathrm{~b}$ it is obvious that in this case the optical power division is proportional.

To achieve symmetrical distribution of the optical power between three output waveguides, the rectangle spacing needs to have optimal dimensions and it must be placed into an exactly defined position, which provides symmetrical distribution of electromagnetic field at the end of the tapered channel waveguide, where the signal is divided into the left output branch, to the right output branch and to the straight output branch.

Optimization of location and dimensions of the rectangle is made in relations to distribution of electromagnetic field of the optical modes in the waveguiding structure and it is shown in Fig. 5a.

According to the simulation, the optimized structure with the inserted rectangle of the NOA waveguiding layer and the PMMA substrate at $650 \mathrm{~nm}$ made the output power from the output waveguides $\left(P_{1}, P_{2}\right.$ and $P_{3}$, see Figs. 5b and 6) differing in less than $0.5 \%$. The optimized $1 \times 3 \mathrm{Y}$ splitter had the dimensions of the inserted rectangle $67 \mu \mathrm{m}$ (width), $2800 \mu \mathrm{m}$ (length) and $1000 \mu \mathrm{m}$ (height). The optimized position of the rectangle (i.e., distance from the axes of the splitter) is $120 \mu \mathrm{m}$ and $10 \mathrm{~mm}$ from the end of the input fiber waveguide. This arrangement gave the distribution of the output power for NOA73 waveguide to $33.1 \%\left(P_{1}\right): 33.4 \%\left(P_{2}\right): 33.4 \%\left(P_{3}\right)$, i.e., left, central and right branches, respectively. 

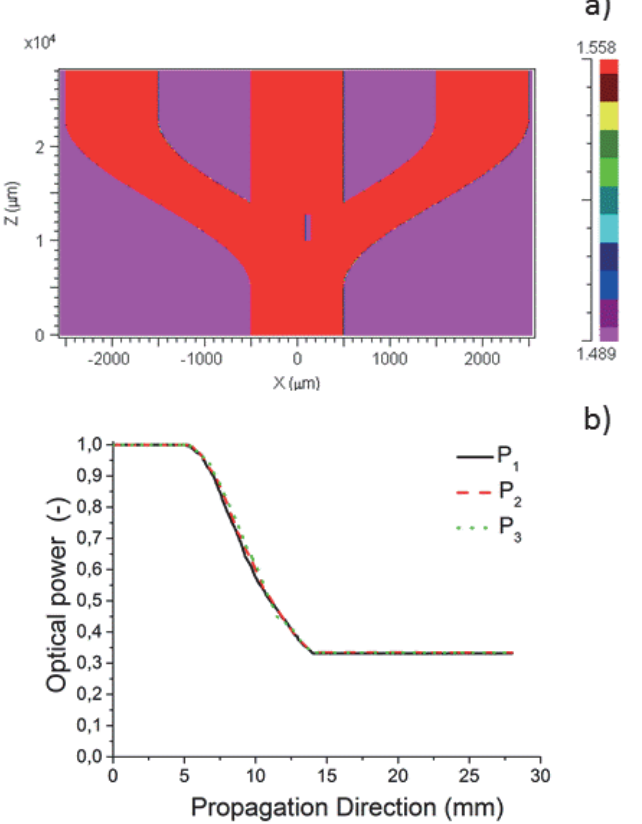

Fig. 5. Results of simulation of the $1 \times 3 \mathrm{Y}$ splitter with photopolymer NOA73 waveguide layer for $650 \mathrm{~nm}$, a) computed index profile (top view), b) normalized optical signal propagation.

a)

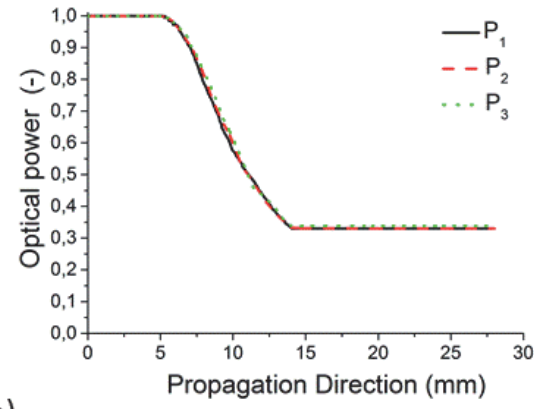

b)

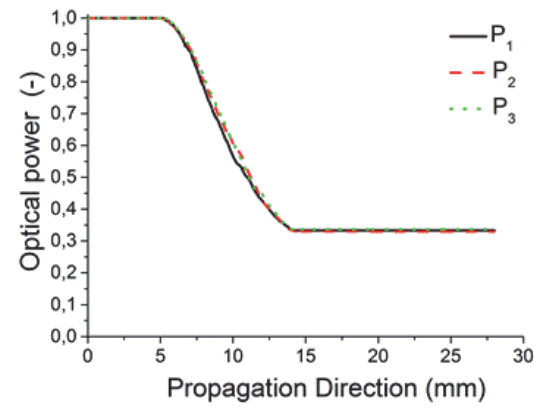

Fig. 6. Normalized optical signal propagation for $650 \mathrm{~nm}$ of the $1 \times 3 \mathrm{Y}$ splitter with rectangle shaped spacing and photopolymer core waveguides a) NOA88, b) NOA1625.

The results of the simulations for the optimized structures with NOA88 and NOA1625 core waveguide are shown in Fig. 6. The simulation was done using the same parameters as above. Fig. 6 a shows propagation of the signal through $1 \times 3 \mathrm{Y}$ splitter with NOA88 core waveguide layer, which has optimized dimensions for refractive indices of 1.557 and, similarly, Fig. 6b shows propagation of the signal splitter with NOA1625 core waveguide layer with optimized dimensions for refractive indices of 1.625 . The modeling was done for a wavelength $650 \mathrm{~nm}$ and refractive index of PMMA substrate was 1.489 . What concerns the splitter with NOA88 the achieved ratio of the power division was $33.1 \%:\left(P_{1}\right): 33.4 \%\left(P_{2}\right): 33.4 \%\left(P_{3}\right)$ and, similarly, for the splitter with NOA1625 it was $33.3 \%$ : $\left(P_{1}\right): 33.0 \%\left(P_{2}\right): 33.6 \%\left(P_{3}\right)$.

Because of almost symmetrical spreading of the signals amongst all the output waveguides, in Fig. 5b and Figs. 6, one can see only one curve of the optical power that consists of overlapping curves of left, central and right branches.

For comparison, we also did modeling for a similar structure without the inserted rectangle and, as expected, such a structure was non-symmetrical with optical power distribution ratio $32 \%\left(P_{1}\right): 36 \%\left(P_{2}\right): 30 \%\left(P_{3}\right)$ for the right, central and left branches, respectively.

\section{Fabrication}

The fabrication process of the designed optical splitters is step by step shown in Fig. 7 and it has been described in our papers [20], [21] as well.

The Y-groove for the waveguide core layer into PMMA substrate was made by using CNC (computer numerical control) NONCO Kx3 milling machine (milling tool size of $0.8 \mathrm{~mm}$, spindle $1800 \mathrm{rpm} / \mathrm{min}$ and moving $36 \mathrm{~mm} / \mathrm{min}$, see Fig. 7a). Then we inserted standard POF waveguides (PFU-UD1001-22V (which were to serve as the input/output waveguides) into the groove (Fig. 7b). The fiber waveguides were, contrary to [20], [21], faced-polished prior to inserting. Next we filled up the taper region with NOA polymer and applied UV curing process (Fig. 7c). Finally, the top cover PMMA is placed onto the structures (Fig. 7d).
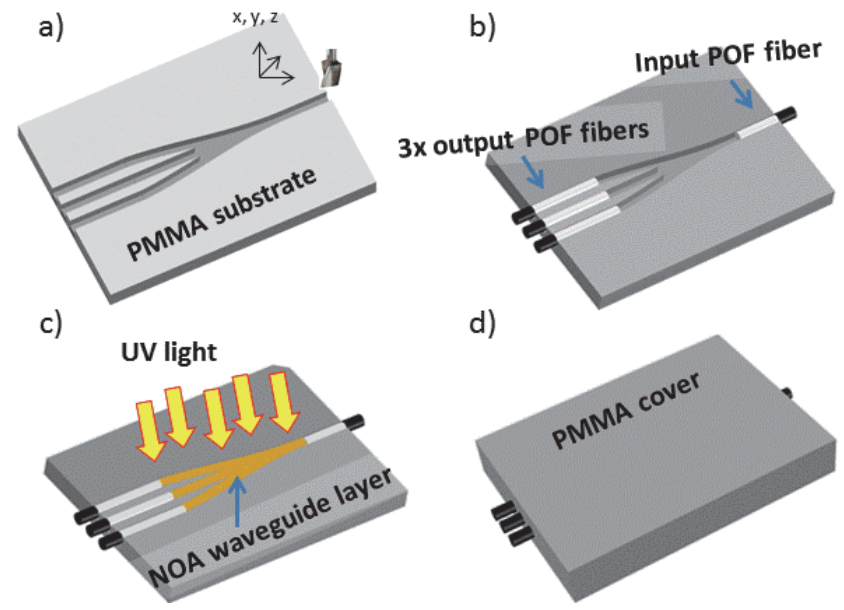

Fig. 7. Fabrication process for the optical splitters, a) $\mathrm{CNC}$ machining into polymer substrate, b) inserting of standard POF waveguide, c) filling up taper region with core layer and applying UV curing process, d) assembling top cover layer. 


\section{Measurements and Results}

Properties of the splitters were checked using optical microscope and the measurement revealed that it had good optical quality and dimension of the fabricated structure corresponded well with the size of the proposed splitters what concerns dimension of input/outputs waveguides, taper region, central and S band waveguides. The dimensions of the inserted rectangle were (due to the used technology) slightly bigger than the proposed one. The images of the fabricated Y-groove structures after the step illustrated in Fig. 7a are shown in Fig. 8a (substrate with $\mathrm{Y}$ groove only) and Fig. 8 b (substrate with $\mathrm{Y}$ groove including rectangle shape spacing). Figures $8 \mathrm{a}$ and $\mathrm{b}$ show the core waveguide layer without the input/outputs POF waveguides and the cover protection layer. Figure 8c shows the final structure with the core waveguide layer, assembling input/output waveguides and the top protection layer.

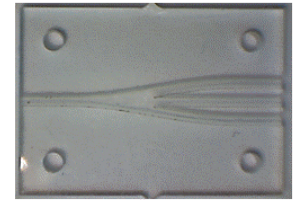

a) $\quad \longmapsto 5 \mathrm{~mm} \quad$ b)

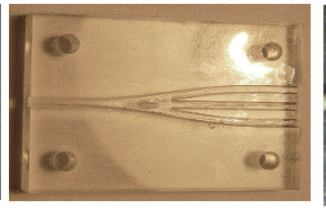

b)

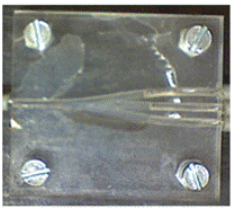

$\longmapsto 5 \mathrm{~mm} \quad \mathrm{c})$ $\longmapsto 5 \mathrm{~mm}$
Fig. 8. Images of PMMA substrate with $1 \times 3$ Y-groove a) substrate with $Y$-groove only, b) substrate with $Y$ groove including rectangle shaped spacing, c) detail of the splitter with waveguide layer and assembled input/output POF waveguide.

Figure 9 shows in a simple visual way how the final three-branch optical power splitter with the rectangle shaped spacing (having assembled POF input and output waveguides and NOA core waveguide layer and cover PMMA layer) transmits the optical light. To demonstrate it, we used the laser tester FLS-240 operating at $635 \mathrm{~nm}$.

The schema of the insertion optical loss measurement is given in Fig. 10. The measurements were done for green light $\left(532 \mathrm{~nm}, \mathrm{Nd}: \mathrm{YVO}_{4}\right.$ laser$)$, red light $(650 \mathrm{~nm}$, laser Safibra OFLS-5 FP-650) and for $850 \mathrm{~nm}$ (laser Safibra OFLS-5 DFB-850).

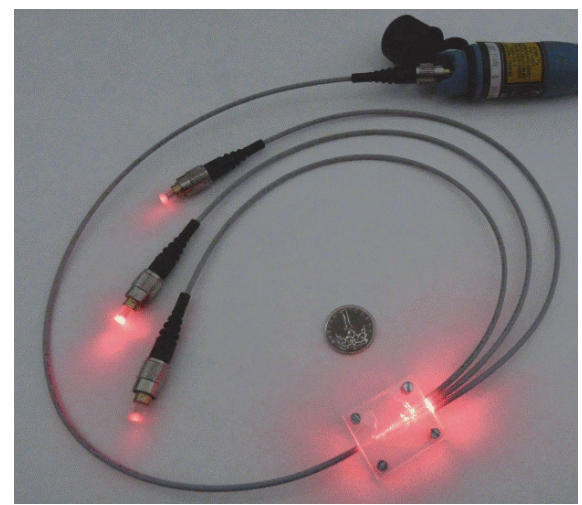

Fig. 9. Images of $1 \times 3 \mathrm{Y}$ splitters transmitting optical signal $635 \mathrm{~nm}$.

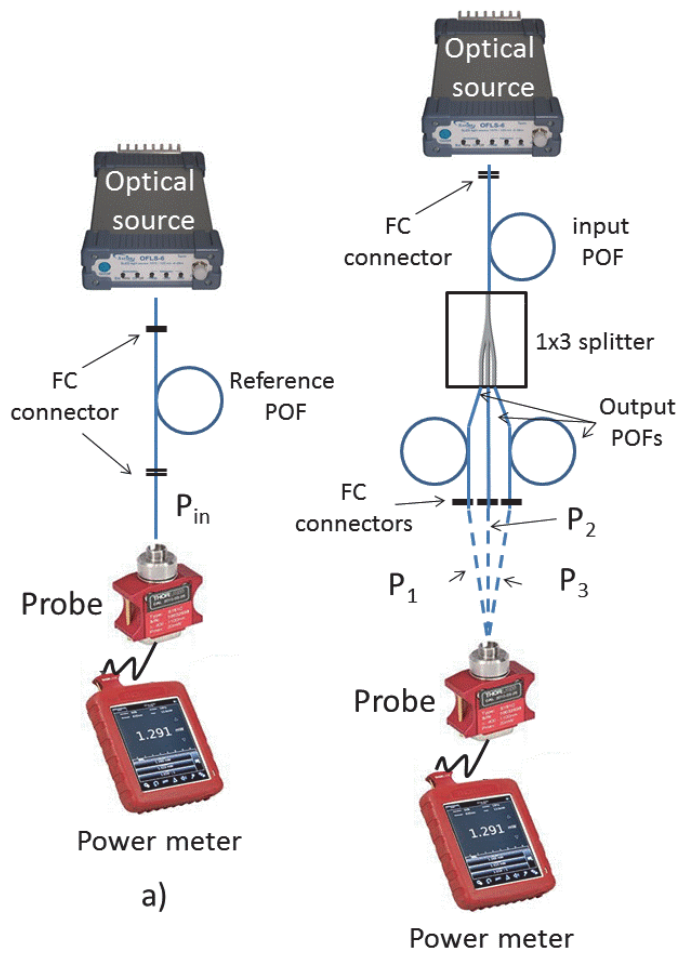

b)

Fig. 10. Set up for insertion optical loss measurement (for details see the text).

The output lights were measured by an optical power meter Thorlabs PM200 with a silicon detector S151C and the accuracy of the set-up is estimated to be $\pm 5 \%$. The measurement started with determining the optical power $P_{\text {in }}$ coming from the source and passing through the reference $30 \mathrm{~cm}$ long POF fiber (see Fig. 10a). Then for $1 \times 3 \mathrm{Y}$ structure, the power was measured separately for the left $\left(P_{1}\right)$, central $\left(P_{2}\right)$ and right $\left(P_{3}\right)$ output branches of the splitter (see Fig. 10b). Input and output POF fibers are $15 \mathrm{~cm}$ long. Then the insertion optical losses were calculated from the equation:

$$
L=-10 \cdot \log \frac{P_{1}+P_{2}+P_{3}}{P_{i n}}[\mathrm{~dB}]
$$

where $P_{\text {in }}$ means optical power after transmission through the reference fiber POF and $P_{1}, P_{2}, P_{3}$ are outgoing optical powers. The obtained data for the samples are summarized in Tab. 2.

\begin{tabular}{|c|c|c|c|c|}
\hline \multirow{2}{*}{ Sample } & \multirow{2}{*}{ Waveguide layer } & \multicolumn{3}{|c|}{$\begin{array}{c}\text { Insertion losses } \\
(\mathbf{d B})\end{array}$} \\
\cline { 3 - 5 } & & $\mathbf{5 3 2} \mathbf{~ n m}$ & $\mathbf{6 5 0} \mathbf{~ n m}$ & $\mathbf{8 5 0} \mathbf{~ n m}$ \\
\hline$\# 233^{*}$ & NOA88 & 4.6 & 4.2 & 3.5 \\
\hline$\# 234^{*}$ & NOA88 & 6.1 & 7.0 & 8.5 \\
\hline$\# 236^{*}$ & NOA73 & 3.0 & 3.6 & 3.7 \\
\hline$\# 251$ & NOA73 & 2.8 & 2.1 & 2.4 \\
\hline$\# 263$ & NOA88 & 4.9 & 3.5 & 4.5 \\
\hline$\# 272$ & NOA73 & 3.7 & 2.7 & 2.8 \\
\hline$\# 273$ & NOA88 & 5.6 & 5.8 & 5.8 \\
\hline
\end{tabular}

* reference samples without insertion of rectangle shaped spacing

Tab. 2. Insertion optical losses of the $1 \times 3 Y$ splitters. 
The measurement of optical insertion losses proved that $1 \times 3$ Y PMMA/NOA73 splitter had optical losses lower than $4 \mathrm{~dB}$ for all three wavelengths and reached down to $2.8 \mathrm{~dB}$ at $532 \mathrm{~nm}, 2.1 \mathrm{~dB}$ at $650 \mathrm{~nm}$ and $2.4 \mathrm{~dB}$ at $850 \mathrm{~nm}$ (the sample \#251, see Tab. 2). Optical losses of the $1 \times 3 \mathrm{Y}$ PMMAS/NOA88 splitters were slightly higher and reached $4.9 \mathrm{~dB}$ at $532 \mathrm{~nm}, 3.5 \mathrm{~dB}$ at $650 \mathrm{~nm}$ and $4.5 \mathrm{~dB}$ at $850 \mathrm{~nm}$ (the sample \#263, see Tab. 2).

Comparing our new splitters that had inserted rectangles with a reference structure without any rectangle, we found that the latter exhibited strongly non-proportional distribution of optical power and, as expected, the most of the energy was gathering in the central branch. The experimentally found non-proportionality was in reality much stronger than it followed from the simulation. For instance, in the case of NOA88 multimode 1x3Y splitter the simulation showed the coupling ratio $33.0 \% P_{1}: 36.1 \%$ $P_{2}: 30.8 \% P_{3}$ while the experiment revealed that actually it was $27.0 \% P_{1}: 54.0 \% P_{2}: 19.0 \% P_{3}$ (the sample \#234, see Tab. 2), (i.e., measured deviation from symmetrical division of optical power was $\pm 20.4 \%$.).

Our experimental splitters with rectangular shape spacing exhibited optical power division much more proportional comparing with the above mentioned splitters without inserted rectangular. Insertion of the rectangle into the center of the tapered waveguiding region provided better distribution of optical power and the splitters exhibited optical power coupling ratio as good as $31.8 \%$ $\left(P_{1}\right): 37.3 \% \quad\left(P_{2}\right): 30.9 \% \quad\left(P_{3}\right) \quad$ (right branch : central branch : left branch) (the sample \#273, see Tab. 2), which means that the difference between the measured deviation from symmetrical division of optical power was $\pm 12.7 \%$. However, as the results expected from the simulation were more optimistic, we believe that there are still some possibilities to improve the real structures by solving technical parameters of the fabrication.

\section{Conclusion}

We designed, realized and measured properties of multimode polymer $1 \times 3 \mathrm{Y}$ power splitters. The design was done by beam propagation method using RSoft software. For the splitters we used NOA73 and NOA88 core waveguide layers and substrate and cover protection layers were made of PMMA. The designed structures were then realized by $\mathrm{CNC}$ engraving and the waveguiding pattern was hardened by the UV radiation.

The measurement of optical insertion loss proved that the PMMA/NOA73 1x3Y splitter had the lowest insertion loss $2.1 \mathrm{~dB}$ at $650 \mathrm{~nm}$ and $2.4 \mathrm{~dB}$ at $850 \mathrm{~nm}$; and optical loss of the PMMA/NOA88 splitter was $3.5 \mathrm{~dB}$ at $650 \mathrm{~nm}$.

Both, simulation and realization of the splitters showed the important role of insertion a rectangle into the central waveguiding region. The distribution of the optical power was this way improved up to the ratio of the output powers $31.8 \%\left(P_{1}\right): 37.3 \%\left(P_{2}\right): 30.9 \%\left(P_{3}\right)$ for the left, central and right output branches, respectively, which is much better comparing with the structures without the inserted rectangle.

The results of the simulations, however, shows, that there are still some reserves in the technological procedures that may make the parameters of the real structures even better.

\section{Acknowledgments}

Our research is supported by the research program of the Czech Technical University in Prague by project no. SGS14/195/OHK3/3T/13.

\section{References}

[1] DeCUSATIS, C. Handbook of Fiber Optic Data Communication: A Practical Guide to Optical Networking. Elsevier, 2008. ISBN: 978-0-12-374216-2

[2] REED, G. T. Silicon Photonics the State of the Art. John Wiley \& Sons Ltd., 2008. ISBN: 978-0-470-02579-6

[3] BANBA, S., OGAWA, H. Novel symmetrical three-branch optical waveguide with equal power division. IEEE Microwave and Guided Wave Letters, 1992, vol. 2, no. 5, p. 188-190. ISSN: 10518207. DOI: $10.1109 / 75.134350$

[4] LIN, H.B., WANG, Y.H., WANG, W.S. Singlemode 1x3 integrated optical branching circuit design using microprism. Electronics Letters, 1994, vol. 3, no. 5, p. 408-409. ISSN: 00135194. DOI: $10.1049 / \mathrm{el}: 19940260$

[5] WANG, T.J., HUANG, C.F., WANG, W.S. Wide-angle 1x3 optical power divider in $\mathrm{LiNbO}_{3}$ for variable power splitting. IEEE Photonics Technology Letters, 2003, vol. 15, no. 10, p. 1401 to 1403. ISSN: 1041-1135. DOI: 10.1109/LPT.2003.818256

[6] YABU, T., GESHIRO, M., MINAMI, N., SAWA, S. Symmetric three-branch optical power divider with a coupling gap. Journal of Lightwave Technology, 1999, vol. 17, no. 9, p. 1693-1699. ISSN: 0733-8724. DOI: $10.1109 / 50.788576$

[7] SOLDANO, L.B., PENNINGS, E.C.M. Optical multi-mode interference devices based on self-imaging - principles and applications. Journal of Lightwave Technology, 1995, vol. 13, no. 4 , p. 615-627. ISSN: 0733-8724. DOI: $10.1109 / 50.372474$

[8] IBRAHIM, M.H., SHUH-YING, L., MEE-KOY, C., KASSIM, N.M., MOHAMMAD, A.B. Multimode interference optical splitter based on photodefinable benzocyclobutene, (BCB 4024-40) polymer. Optical Engineering, 2007, vol. 46, no. 1, p. 013401-1013401-4. ISSN: 0091-3286. DOI: DOI:10.1117/12.850593

[9] ZIGANG, Z., DUAN, X. Integrated waveguide splitter fabricated by $\mathrm{Cs}^{+}-\mathrm{Na}^{+}$ion-exchange, Optics Communications, 2006, vol. 266, no. 1, p. 129-13. ISSN: 0030-4018. DOI: 10.1016/j.optcom. 2006.03.023

[10] SINGH, G., SIROHI, A. K., VERMA, S. Estimation of the performance of a 3-dB Y-junction optical coupler with a channel profile of proton-exchanged lithium niobate. Physics of Wave Phenomena, 2013, vol. 21, no. 3, p. 201-206. ISSN: 1541-308X. DOI: $10.3103 / \mathrm{S} 1541308 X 13030059$

[11] SAKAI, A., FUKAZAWA, T., TOSHIHIKO, B. Low loss ultra small branches in silicon photonic wire waveguide. IEICE 
Transactions on Electronics, 2002, vol. E85-C, no. 4, p. 1033 to 1038. ISSN: $1745-1353$.

[12] BOOTH, B. L. Low-low channel wave-guides in polymers. Journal of Lightwave Technology, 1989, vol. 7, no. 10, p. 1445 to 1453. ISSN: 0733-8724. DOI: $10.1109 / 50.39079$

[13] MA, H., JEN, A.K.Y., DALTON, L. R. Polymer-based optical waveguides: Materials, processing, and devices. Advanced Materials, 2002, vol. 14, p. 1339-1365. ISSN: 0935-9648. DOI: $10.1002 / 1521-4095(20021002) 14$

[14] BetTiOl, A. A., SUM, T. C., CHEONG, F. C., SOW, C. H., RAO, S. V., van KAN, J. A., TEO, E. J., ANSARI, K., WATT, F. A progress review of proton beam writing applications in microphotonics. Nuclear Instruments \& Methods in Physics Research Section B-Beam Interactions with Materials and Atoms, 2005, vol. 231, p. 364-371. ISSN: 0168-583X.

[15] WONG, W. H., LIU, K. K., CHAN, P. S., PUN, E.Y.B. Polymer devices for photonic applications. Journal of Crystal Growth, 2006, vol. 228, p. 100-104. ISSN: 0022-0248. DOI: $10.1016 /$ j.jcrysgro.2005.12.017

[16] LYUTAKOV, O., TUMA, J., PRAJZLER, V., HÜTTEL, I., HNATOWICZ, V., ŠVORČ́́K, V. Preparation of rib channel waveguides on polymer in electric field. Thin Solid Films, 2010, vol. 519, no. 4, p. 1452-1457. ISSN: 0040-6090. DOI: $10.1016 /$ j.tsf.2010.08.019

[17] PRAJZLER, V., KLAPUCH, J., LYUTAKOV, O., HÜTTEL, I., ŠPIRKOVÁ, J., NEKVINDOVÁ, P., JEŘÁBEK, V. Design, fabrication and properties of rib poly (methylmethacrylimide) optical waveguides. Radioengineering, 2011, vol. 20, p. 479-485. ISSN: $1210-2512$. DOI: $10.13164 / \mathrm{re}$

[18] PRAJZLER, V., LYUTAKOV, O., HUTTEL, I., BARNA, J., SPIRKOVA, J., NEKVINDOVA, P., JERABEK, V. Simple way of fabrication of epoxy novolak resin optical waveguides on silicon substrate. Physica Status Solidi C, 2011, vol. 1-4. ISSN: 1862-6351. DOI 10.1002/pssc.201084031

[19] PRAJZlER, V., HYNEK, T., ŠPIRKOVÁ, J., JEŘÁBEK, V. Design and modeling of symmetric three branch polymer planar optical power dividers. Radioengineering, 2013, vol. 22, p. 233 to 239. ISSN: 1210-2512. DOI: $10.13164 / \mathrm{re}$

[20] PRAJZLER, V., PHAM, N. K., ŠPIRKOVÁ, J. Design, fabrication and properties of the multimode polymer planar $1 \times 2 \mathrm{Y}$ optical splitter. Radioengineering, 2012, vol. 21, p. 1202-1207. ISSN: 1210-2512. DOI: $10.13164 / \mathrm{re}$

[21] PRAJZLER, V., NERUDA, M., ŠPIRKOVÁ, J. Planar large core polymer optical $1 \times 2$ and $1 \times 4$ splitters connectable to plastic optical fiber. Radioengineering, 2013, vol. 22, p. 751-757. ISSN: 12102512. DOI: $10.13164 / \mathrm{re}$
[22] PRAJZLER, V., MAŠTERA, R., JEŘÁBEK, V. Large core planar $1 \times 2$ optical power splitter with acrylate and epoxy resin waveguides on polydimetylsiloxane substrate. Radioengineering, 2014 vol. 23, no. 1, p. 488-495. ISSN: 1210-2512. DOI: $10.13164 / \mathrm{re}$

[23] BELTRAMI, D. R., LOVE, J. D., LADOUCEUR, F. Multimode planar devices. Optical and Quantum Electronics, 1999, vol. 31, p. 307-326. DOI: $10.1023 / \mathrm{A}: 1006971108806$

\section{About the Authors ...}

Václav PRAJZLER was born in 1976 in Prague, Czech Republic. In 2001 he graduated from the Faculty of Electrical Engineering at the Czech Technical University in Prague at Department of Microelectronics. In 2007 he obtained the $\mathrm{PhD}$ degree from the same university. Since 2014 he has been an Associate Professor of Electronics with the Department of Microelectronic, Czech Technical University in Prague. His current research is focused on design, fabrication and investigation of properties of photonics structures.

Radek MAŠTERA was born in 1989. His bachelor program was reached at the Department of Microelectronics, Faculty of Electrical Engineering, Czech Technical University in Prague in 2012. He obtained his MSc degree from the Department of Measurement, Faculty of Electrical Engineering, Czech Technical University in Prague in 2015 and his thesis dealt with design, fabrications and measurements of properties of optical polymer planar selective wavelength structure for $1 \mathrm{~mm}$ diameter core Plastic Optical Fiber.

Jarmila ŠPIRKOVÁ was graduated from the Faculty of Natural Science at Charles University in Prague and from the Institute of Chemical Technology, Prague (ICTP). Now she is with the Department of Inorganic Chemistry at the ICTP. She has worked there continuously in materials chemistry research and since 1986 she has been engaged in planar optical waveguides technology and characterization. She is the Assistant Professor at the ICTP giving lectures on general and inorganic chemistry. 